\title{
A TWO-DIMENSIONAL NUMERICAL STRATEGY FOR COMPUTING SELF-HEALING CERAMIC MATRIX COMPOSITES LIFETIME
}

\author{
G. Bellezza ${ }^{1 *}$, G. Couégnat ${ }^{2}$, M. Ricchiuto ${ }^{1}$ and G. L. Vignoles ${ }^{2,3}$ \\ ${ }^{1}$ Inria Bordeaux Sud-Ouest, Talence CEDEX, France \\ ${ }^{2}$ Laboratoire des Composites Thermostructuraux (CNRS / Univ. Bordeaux / Safran / CEA), \\ Pessac, France \\ ${ }^{3}$ University of Bordeaux, Talence, France \\ * giulia.bellezza@inria.fr
}

This work investigates the structural evolution and the failure of a self-healing ceramic matrix mini-composite [1] under static fatigue tests in oxidizing environment. The investigation is based on a two-dimensional image-based model of a transverse crack and the description of the related diffusive-reactive phenomena [2]. In particular, the ingress of oxygen and the combined effect of oxidation and production of a sealing liquid oxide are taken into account. A slow crack growth model [3] is used to predict the fibres progressive degradation with respect to the on environmental parameters, especially the oxygen concentration, considering its extreme variation trough the crack. Tow failure depends on the statistical fibres initial strength, slow crack growth kinetic, and load transfer following fibres breakage, which is captured thanks to an approximate mechanical model. This approach has been applied to a virtual material consisting of Hi-Nicalon fibres immersed in an $\mathrm{SiC} / \mathrm{B}_{4} \mathrm{C}$ matrix coating. Effects of temperature, spatial variation of the statistical distribution of fibres strength and applied load were examined in terms of material behaviour and lifetime prediction. The results prove the fundamental impact of the diffusion/reaction processes (healing) on the fibre breakage scenarios, highlighting the need to model these processes appropriately. Besides, we show that the materials lifetime has great sensitivity to the distribution of weak fibres and of their relative positions in the yarn.

\section{Acknowledgement}

This work is funded by the French Research Agency ANR under grant no. ANR-17-CE080030 .

\section{References}

[1] R. Naslain, J. Lamon, R. Pailler, X. Bourrat, A. Guette and F. Langlais (1999) Micro/minicomposites: a useful approach to the design and development of non-oxide CMCs. Composites Part A: Applied Science and Manufacturing, 30, 537-547.

[2] G. Perrot, G. Couégnat, M. Ricchiuto, G. L. Vignoles (2019) Image-based numerical modeling of self-healing in a ceramic-matrix minicomposite. Ceramics, 2, 308-326.

[3] P. Ladevèze and M. Genet (2010) A new approach to the subcritical cracking of ceramic fibers. Composites Science and Technology, 70, 1575 - 1583. 